\title{
How to Take Advantage of Computer Technology in Physical Education
}

\author{
$\operatorname{Min} \mathrm{Li}^{1}$ \\ ${ }^{1}$ Jiangxi Science and Technology Normal University, Nanchang 330013, China
}

Keywords: Physical education, Computer technology, Takes advantage

\begin{abstract}
With the progress and development of society, the application of computer technology has penetrated into our life. Based on the analysis of overall perspective, it will greatly improve the productivity and development of technology, which is the inevitable demand of times. In the process of physical education teaching-learning, the introduction and usage of computer technology will effectively promote the implementation of physical teaching activities. This paper will discuss how to take advantage of computer technology in physical education.
\end{abstract}

\section{Introduction}

The developments of computer technology provide necessary technical support for teaching activities. It has been widely applied in current teaching process, which greatly promote the class efficient of teaching activity in one side, and keep pace with the times, exploration and innovation in the other side. The application of computer technology is an inevitable trend of teaching activities, and also is the route education reformation must take. In the process of physical education, the application of computer technology can effectively avoid the restriction of space, instruments etc. thus promote the activity carry out in a high-quality.

\section{How to take advantage of computer technology in physical education}

Using computer technology to promote the quality of preparation for physical education. $\mathrm{PE}$ teacher's lesion preparation for physical education is an important safeguard for the stability and order of teaching activities. In the preparation, the carding and supplement of teaching content is the keystone of work. A preparation in high quality can greatly enrich its teaching content and avoid boring, stimulating student's learning interest and explaining the profound things in a simple way to realize an efficient input of teaching content. In the traditional PE, the preparation work of most teacher are based on existent materials and teacher's books, which in a large extent results the course monotone, and students lack of motivations and interests, and this tradition is deviate from its original intention of improve and enhance students' habitus and for them, the PE is more often a time of after school and relax. In addition, in some teaching units and organizations, it is prevalence of pay no attention on physical education activities which lacking of organization and content and hardly achieves effective development. The application of computer technology can effectively broaden the data collection channels of teacher and greatly improve the enjoyment of PE, stimulating students' interest of learning in teaching methods. The application of computer technology can improve the quality of physical education, providing great support for later learning courses.

Using computer technology to improve the overall office efficient of PE. Physical education concerns with many aspects. The lesion preparation and the classroom teaching of physical education activity, together with inductive analysis of students' achievements after class are 
important part and content of teaching activities. The record of students' achievement of physical education and analyzing of their habitus specifically is the objective requirement of PE's scientific and modernization in a new era. With the development of PE, it asks more sport activities what largely increased the burden of PE teachers and affects their teaching efficient, which is bad for their personal improvement of the unfold of teaching activities. In computer technology, some related software can help teachers to complete relative works effectively, recording, analyzing and summarizing students' information, which in a large extent can reduce the burden of teachers who can save more energy into teaching activities and facilitate the overall office efficient and promote the unfold of relating teachings.

Using computer technology to establish a campus-wide professional sports site. In the traditional physical education activities, the majority of teaching is only based on classroom teaching, and students are insufficient in receiving teaching information and the access of multi-channel of knowledge, which limited the better carry out of PE activities. The establish of campus-wide professional sports site by using computer technologies will broaden the channels of students' knowledge, exploring more teaching methods, meanwhile, it is capable to break the limitations of space and time to ensure students get more sports knowledge. And the timely updates and supplements of content in the website can increase the continuity of website using, in other words, improving their self-learning abilities and based on personal requirement to obtain and sorting information as a kind of abilities. In addition, the construction of campus sport website provide a new communication platform for teachers and students, improve its productivity and timely solve the problems caused by insufficient connect and make sure the seamless connection between them and promoting the efficiency of teaching.

Using computer technology to promote the classroom quality of PE. In the theory curriculum of physical education, the using of multimedia teaching relying on computer technology, enable students to understand and grasp the sport teaching content more intuitive and convenience. The theory curriculum has several features like the master of theoretical knowledge is greater than the memory, the rather dull teaching content and others in which process most students are prefer to activity class and lack of sufficient interest and patience to relevant theories and concepts, even ignoring them and influenced the application and realization of certain teaching arrangements and targets. In the contrast, we should highlight the enjoyment and richness of theory teaching to stimulate students' interest to learn more actively and obtain relevant sports knowledge. In theoretical teaching, the scientific usage of computer technology can effectively solve problems. In the process, the technology should fully applied, using course PowerPoint, video player, related software to assisted class teaching which bring a new classroom experience, in which can greatly enhance students' learning intentions and improve the master of sports theoretical knowledge in a variety stimulation of sensory. What's more, teachers need to pioneer their thinking and break out of the existing models and keep innovation bravely. For example, when explain the relevant knowledge of tennis, they can explain with the video about Li Na competed intensely with other players in Australian Open, and when explain distance race and sprint, the video of World Marathon and sprinter Liu Xiang's classical game videos and introducing related sports knowledge present in the professional world-class players. By this way, the teacher could fully mobilize the teaching atmosphere and ensure students to obtain a clear understanding of relevant physical theories, they can also exploring more positively by discussing and analyzing the related professional knowledge in the game videos to teaching students.

Using computer technology to assist students to standardize their sports technical action. The application of computer technology can efficiently provide references for sports technical 
action. In the imaging system, we can clearly see the track of correlated technical actions in students' sports activities, the sub-type or slow-type play of the action enable people timely discover it's insufficient and facilitate the targeted training and grasp the essentials of the action. It also presented in a detailed breakdown of the specification action, to facilitate students' direct master of the action. The computer technology depend on the latest scientific analysis system, they can decompose and analyzing students' relevant technical action or action indicators then summarizing their personal characteristics and training differently.

With the progress of international community, modern competitive sports are facing more intense competitions. How to get more training growth space and competition in sport training and competition and ensure its objectivity? It has become the objective request of modern competitive sports. The application of computer technology in sports training and competition has greatly improved the efficiency and scientific of training and its fairness and orderliness.

\section{Conclusion}

In modern education, the application of modern science and technology is very important, it is the objective needs of the development of education, and the inevitable requirement of social progress. The application of computer technology in physical education is an inevitable trend of teaching development, which can greatly facilitate the conduct of educational work and promoting its teaching quality and efficiency.

\section{References}

[1] Cui Z. How to take advantage of computer technology in physical education?. Bulletin of Sport Science \& Technology, 2014, 13: 129-131. (In Chinese)

[2] Qian L. How to take advantage of computer technology in college sporting?. Electronic Test, 2014, S2: 259-260. (In Chinese)

[3] Huang S. On the application of computer assisted instruction in physical education teaching. New technology and new product of China, 2012, 01: 239. (In Chinese)

[4] Gao J. Analysis and consideration of computer assisted instruction in physical technical course. Science and Technology Information, 2008, 36: 280-281. (In Chinese) 